\title{
International Mobility of Canadian Social Sciences and Humanities Doctoral Students
}

\author{
Jane Knight \\ Meggan Madden \\ Ontario Institute for Studies in Education, University of Toronto
}

\begin{abstract}
International academic mobility is an aspect of internationalization that is changing rapidly in terms of volume, scope, and impact. Although much of the attention and research on mobility has focused on undergraduate students participating in short-term study abroad, internships, and exchange experiences, the new push to develop international research partnerships and networks has led to the recognition of the importance and benefits of doctoral student mobility. The purpose of this article is to provide a current picture of the international mobility - both full-degree and short-term research and academic work abroad - of Canadian students in social sciences and humanities (SSH). The analysis focuses on the profile of internationally active SSH doctoral students, and the rationales that drive academic mobility, the factors that help or hinder it, and the types of scholarships available to support it.
\end{abstract}

\section{RÉSUMÉ}

La mobilité internationale académique est l'un des aspects de la mondialisation qui évolue le plus en termes de nombres, d'étendue et d'impact. La plus grande partie des recherches sur la mobilité est effectuée auprès des étudiants du premier cycle participant aux études à court terme à l'étranger, aux stages, et aux programmes d'échanges. Ce n'est que récemment que l'importance et les bénéfices de la mobilité des étudiants au troisième cycle ont été reconnus étant donné la nouvelle poussée vers le développement de partenariats et de réseaux internationaux de recherches. Le but de cet article est de peindre une image actuelle de la mobilité internationale - y compris les licences complètes, les recherches à court terme ainsi que les travaux universitaires à l'étranger -- des étudiants canadiens en sciences sociales et humaines (SSH). L'analyse est axée sur le profil des étudiants au troisième cycle en SSH et actifs au niveau international, sur les justifications menant à la mobilité académique, sur les facteurs facilitant ou entravant cette mobilité, et les types de bourses disponibles pour l'appuyer. 


\section{INTRODUCTION}

As the 21st century progresses, the international dimension of higher education is becoming both more important and more complex. The changing world of internationalization brings new opportunities, new benefits, new risks, and new challenges, all of which are contributing to the current state of turbulence in the higher education sector around the world (Knight, 2008). International academic mobility is the aspect of internationalization that is changing the most in terms of volume, scope, and impact (Bhandari \& Blumenthal, 2009). Although students and scholars have been mobile for years, if not centuries, the emergence of globalization has precipitated an increase in the demand for and the importance of student mobility.

Europe is well known for its Erasmus (European Region Action Scheme for the Mobility of University Students) program. Since 1987, 2 million students have received Erasmus mobility grants, and this number is expected to reach 3 million by 2012 (European Commission, 2010). These numbers are eloquent testimony to the priority that Europe gives to supporting students' international academic experiences. The situation in Canada, however, is less clear for two main reasons: the lack of any national- or provincial-level tracking measures to systematically monitor international Canadian student mobility; and the fact that much of the attention and research on mobility has focused on undergraduate students participating in short-term study abroad, internships, and exchange experiences. Only recently has the importance and benefits of graduate-level mobility been recognized, largely due to the new push to develop international research partnerships and networks (Natural Sciences and Engineering Research Council [NSERC], 2009; Social Sciences and Humanities Research Council [SSHRC], 2005, 2006).

International academic mobility can bring diverse benefits at the individual, institutional, and national levels (Dwyer \& Peters, 2004). At the individual level, full-time and short-term academic mobility can help to develop globally aware, linked, and competitive Canadian doctoral students in their research and careers. Internationally engaged graduate students can contribute a Canadian perspective to the production, sharing, and transfer of knowledge around the world. Academic mobility also enriches the personal experiences of doctoral students by developing intercultural awareness and a deepening understanding of critical world issues (Teichler, 2004). At the institutional level, Canadian universities not only gain global exposure and academic partnerships through the international mobility of their doctoral students but also benefit from international comparative perspectives that returning doctoral students bring to their home campus, as well as from continuing partnerships with foreign institutions. At the national level, the academic mobility of Canadian doctoral students supports global knowledge sharing, congruent with Canada's science and technology strategies to "excel at connecting to the global supply of ideas, talent, and technologies" (Industry Canada, 2007, p. 85). The participation of doctoral students in global knowledge sharing can support these strategies to increase Canada's presence in global academic, public, and private sectors.

\section{PURPOSE AND OUTLINE}

This article is based on a study funded by the Social Sciences and Humanities Research Council of Canada (Knight \& Madden, 2008) to review and assess international 
academic mobility trends and participation rates of doctoral students. The purpose of this article is to provide a current picture of the international mobility of Canadian doctoral students in social sciences and humanities (SSH). The authors' analysis focuses on the profile of internationally active SSH doctoral students, as well as the rationales that drive their academic mobility, the factors that hinder or help it, and the types of scholarships available to support it. The first section of the article profiles academically mobile Canadian SSH students specifically, by examining gender, age, discipline, destination country, and areas of research interest. The second section offers an analysis of the rationales and factors that guide and influence these students' decisions to study abroad. This analysis is followed by a detailed examination of the kind of scholarships and funding currently available to Canadian graduate students who wish to have an international academic experience. The final section discusses implications for policy and research and suggests issues that require further attention.

\section{STUDY METHODOLOGY}

The objective of the study was threefold: first, to understand the profile of internationally mobile SSH Canadian doctoral students; second, to examine the rationales, motivations, factors, and barriers for Canadian doctoral students to study abroad; third, to analyze the scholarships available to Canadian SSH doctoral students for studying abroad.

Few data are available on the international mobility of SSH doctoral students in Canada, particularly on their short-term mobility. To develop an accurate profile of the mobility of these students, the SSHRC scholarship programs' database was used as the primary data source; this database includes information on SSHRC's Doctoral Fellowship recipients and its Canada Graduate Scholarship (CGS) awardees. To broaden the profile, data was accessed from education studies produced by the Organization for Economic Co-operation and Development [OECD] (2006, 2008), UNESCO (2006), Statistics Canada (2007), and the Association of Universities and Colleges of Canada (AUCC) (2007).

To gain an understanding of students' rationales and motivations for international mobility, a series of questions was integrated into a national student survey conducted in 2008 to evaluate the CGS program (Gauthier, 2009). The survey included a sample of master's and doctoral level CGS awardees and Fellowship recipients from Canada's three granting councils. The data used in this article are responses from participating SSHRC doctoral students.

To comprehend the factors involved in and the barriers to studying abroad, a literature review was conducted to identify obstacles, benefits, and challenges related to studying abroad. Qualitative research was conducted to understand themes in the experiences of internationally mobile doctoral students, especially those participating in scholarship programs managed by the Canadian Bureau for International Education. Reports conducted by UNESCO, AUCC, and NORFACE (New Opportunities for Research Funding Co-operation in Europe; http://www.norface.org) were the primary sources for identifying factors and barriers (Ackers, Bill, \& Guther, 2008; AUCC, 2007; UNESCO, 2006).

To catalogue the scholarships available to SSH doctoral students, a comprehensive website review was conducted of institutional, provincial, national, and international 
scholarship programs for SSH graduate students. Scholarship programs with explicit and implicit eligibility requirements that allowed for international experiences were included in the catalogue.

\section{Mobility Terminology}

International mobility experiences are part of the overall internationalization process of higher education, particularly graduate training and research. For the purposes of this discussion, mobility experiences are organized into two main categories: 1) full degree at a university outside of Canada; and 2) short-term international mobility experiences while registered in a Canadian higher education institution. Examples of shortterm international mobility activities include taking specialized courses or training, collecting data, conducting joint research or fieldwork, attending a seminar or conference, participating in networking activities, and completing language instruction.

Terminology to describe short-term international mobility experiences is under debate. Current terms for describing undergraduate mobility, such as study abroad, semester abroad, and exchange students, do not adequately address short-term doctoral mobility, since graduate students typically engage in research collaboration, data collection, workshops, and conferences rather than coursework per se.

\section{PROFILE OF CANADIAN SSH DOCTORAL STUDENTS}

According to the 2005 Statistics Canada Survey of Earned Doctorates, SSH earned doctorates made up approximately 38\% of the total earned doctorates. Of those 38\% of earned doctorates, 65\% were in the social sciences and 35\% were in the humanities. Using the same survey, Gluszynski and Peters (2005) found that students who completed SSH doctoral studies were typically older (39 years) than the average Canadian doctoral student (36 years) and that the average completion time for SSH doctoral students was the same as that for the total population of doctoral students (approximately six years). Gluszynski and Peters also reported that 55\% of SSH doctoral students reported having debt on completion of their studies, compared to $44 \%$ of the total population with earned doctorates that report having debt upon completion. The gender breakdown for earned SSH doctorates (58\% women; 42\% men) differed from that of the total group of earned doctorates (47\% women; 53\% men). Age, debt load, and gender have implications for participation in full degree abroad and short-term international mobility experiences.

\section{PROFILE OF SSHRC SCHOLARSHIP APPLICANTS}

Before discussing the profile of SSHRC scholarship applicants and recipients, it is important to briefly describe the scholarship programs. The SSHRC Fellowship is $\$ 20,000$ a year; the Canada Graduate Scholarship (CGS) is $\$ 35,000$ a year. The CGS is only awarded to full-time students enrolled in Canadian institutions, while the Fellowship is granted to students enrolled full-time in Canadian or foreign universities. In 2008, the CGS program announced that an additional award would be available to CGS recipients - \$6,000 to study one term abroad - but it was not available at the time this study was completed. Although several awardees have international experiences prior to receiving the Fellowship or CGS, international study is not a prerequisite for these awards. 
From 2002 to 2007, the profile of students who applied for and received a SSHRC Doctoral Fellowship was generally comparable to that of the population of Canadian SSH students in terms of age and gender. The average age at time of application was 31 years, which means that projected completion would be comparable to the average age of an earned doctorate. ${ }^{1}$ Of the recipients of the two SSHRC scholarships (Fellowship and CGS), $62 \%$ were female and 38\% were male.

On the application, SSHRC scholarship applicants are asked to indicate the geographical region of their research interests, and it is noteworthy that approximately $28 \%$ of SSHRC fellows and 25\% of CGS recipients had research interests involving countries outside of North America, with Europe being the favoured region, followed by Asia Pacific (Knight \& Madden, 2008). This finding is compelling evidence that compared to the number of students who actually participate in a full degree abroad, a sizeable number of doctoral students were interested in a short-term mobility experience to complete their research related to various countries of the world.

\section{PROFILE OF SSHRC DOCTORAL FELLOWS INVOLVED IN FULL-TIME INTERNATIONAL MOBILITY}

Analysis of the SSHRC data base found that from 2002 to 2007, about 20\% of SSHRC doctoral fellows took their full degree abroad (Knight \& Madden, 2008). The profile of those doctoral students is comparable to the total population of Canadian SSH doctoral students in terms of gender and discipline.

Table 1

Profile of SSHRC Doctoral Fellows

\begin{tabular}{|c|c|c|c|}
\hline & $\begin{array}{l}\text { Total SSHRC Doctoral } \\
\text { Fellows }\end{array}$ & $\begin{array}{l}\text { SSRHC Doctoral Fellows } \\
\text { in Canada }\end{array}$ & $\begin{array}{l}\text { SSHRC Doctoral Fellows } \\
\text { outside Canada }\end{array}$ \\
\hline Gender & $\begin{array}{l}62 \% \text { female } \\
38 \% \text { male }\end{array}$ & $\begin{array}{l}64 \% \text { female } \\
36 \% \text { male }\end{array}$ & $\begin{array}{l}56 \% \text { female } \\
44 \% \text { male }\end{array}$ \\
\hline Discipline & $\begin{array}{l}\text { 41\% Humanities } \\
\text { 56\% Social Science } \\
\text { 3\% Interdisciplinary }\end{array}$ & $\begin{array}{l}\text { 38\% Humanities } \\
\text { 59\% Social Science } \\
\text { 3\% Interdisciplinary }\end{array}$ & $\begin{array}{l}\text { 53\% Humanities } \\
\text { 45\% Social Science } \\
\text { 2\% Interdisciplinary }\end{array}$ \\
\hline
\end{tabular}

\section{Gender}

As noted in Table 1, more female SSHRC fellows (56\%) than male fellows (44\%) took their doctoral studies abroad from 2002 to 2007. The larger number of women going abroad for their full doctoral degree was consistent with a similar trend in undergraduate study abroad. The ratio of female to male SSHRC fellows studying in Canada was 64/36, compared to the ratio of 56/44 for full-degree-abroad students. This difference raises the question of whether gender-related issues might deter female students from considering doctoral studies abroad, even though females generally outnumber males.

\section{Discipline}

The ratio of humanities and social science SSHRC fellows studying outside of Canada was $53 / 45,{ }^{2}$ which is notable considering that the ratio of total SSHRC fellows 
was 41/56, which means there were fewer humanities Fellowship students overall. This ratio of students studying outside Canada in the humanities and social sciences differed from world trends, as normally more social science students study outside their home country than humanities students (OECD, 2008).

\section{Destination Country}

The country of destination of students studying outside Canada in the humanities and social sciences was consistent with world trends, however, SSHRC doctoral fellows chose the United States (65\%) and the United Kingdom (26\%) as their most-favoured destinations, followed by France (4\%), Australia (1\%), Germany (1\%), and other countries (3\%) (Knight \& Madden, 2008). These destinations reveal a definite bias toward studying in countries where one of Canada's official languages is spoken and reflect a desire to pursue doctoral studies where the education system is of high quality and comparable to that of Canada. SSHRC doctoral fellows are similar to other students who participate in international academic experiences in that their five countries of choice - the United States, the United Kingdom, France, Australia, and Germany - receive 70\% of globally mobile students (UNESCO, 2006, p. 134; Verbik, 2007). The summary report on the 2007 NORFACE study on European doctoral students in the social sciences explained that the United States, the United Kingdom, Germany, and France attract a high percentage of academically mobile students because of the reputation and prestige of the universities in these countries (Akers et al., 2008). The OECD's publication Education at a Glance and the AUCC's 2007 study Canadian Universities and International Student Mobility reported that the primary considerations for studying abroad include language of instruction, similarity of educational system, academic traditions, and geographical proximity, which explains why the United States is the most popular destination for Canadian students (AUCC, 2007; Jaschik, 2007; OECD, 2008).

The percentage of SSHRC doctoral fellows (65\%) who chose to study in the United States is similar to the statistic reported in UNESCO's Global Education Digest (2006), which indicated that almost 70\% of Canadian students who took full degrees abroad went to the United States. Unfortunately, the UNESCO statistics do not differentiate among undergraduate, master's, and doctoral students.

The AUCC (2007) survey indicated high levels of support for and interest by students to study abroad. The overall percentage of Canadian students studying full time out of country was approximately 1.9\% of the total (including undergraduate and graduate) student population, which was higher than the United States (0.9\%) and comparable to some European countries - the United Kingdom (0.6\%) and France $(1.4 \%)$ - but lower than other European countries, such as Norway (5.6\%), Austria (2.5\%), and Finland (2.9\%) (UNESC0, 2006).

Overall, the profile of Canadian SSH doctoral students shows that they exhibit slightly different characteristics than the total population of Canadian doctoral students who earn doctoral degrees in Canada. SSH doctoral students are older, more likely to be female, and may carry more debt load. These trends may highlight unique obstacles to studying abroad. 


\section{ANALYSIS OF RATIONALES AND FACTORS INFLUENCING DECISIONS TO STUDY ABROAD}

In early 2008, applicants and recipients of CGS and Tri-Council scholarships were surveyed to gain student feedback on scholarship support, the status of scholarship applicants, and the effects of obtaining or not obtaining the scholarship (Gauthier, 2009). The Tri-Council is composed of Canada's three research councils: the Canadian Institutes of Health Research (CIHR), the Natural Science and Engineering Research Council (NSERC), and the Social Sciences and Humanities Research Council (SSHRC). Six of the survey questions related to previous international academic experiences; four questions related to the importance of and rationales for studying abroad and two questions related to factors that would impact international academic mobility.

\section{Previous International Academic Experience}

Previous international academic experience is important to examine as it tends to be an indicator of future study and research abroad. In the survey, students were asked: "At any point during your post-secondary education, have you had any academic experiences outside of Canada, for example, data collection, courses, fieldwork, internships, language study?" Of the survey respondents from all three councils, including master's and doctoral students, about $44 \%$ had previous international academic experience. Unfortunately, no comparable data exist for the general graduate student population in Canada; however, this statistic would suggest that Tri-Council applicants and recipients, who are generally high achievers, are very interested and active in international academic mobility. As illustrated in Table 2, the SSHRC students stood out as being the most internationally mobile students, compared to the NSERC and CIHR students. When the SSHRC percentages were disaggregated, 64\% of the doctoral fellows and 52\% of the CGS doctoral recipients who answered the survey had had previous international academic experience.

Table 2

Previous International Academic Experiences by Research Council

\begin{tabular}{lll}
\hline Research Council & Yes & No \\
\hline All survey respondents & $44 \%$ & $56 \%$ \\
SSHRC students & $53 \%$ & $47 \%$ \\
NSERC students & $48 \%$ & $51 \%$ \\
CIHR students & $32 \%$ & $68 \%$ \\
\hline
\end{tabular}

Importance of and Rationales for Studying Abroad

Understanding students' rationales for international academic mobility experiences is both important and revealing. The first two of the four survey questions that related to the importance of and rationales for study abroad asked students to agree or disagree on how important international academic experiences are to 1) their graduate education and 2) their career path. The third question asked students to express their views on rationales for international academic experiences, such as data collection, 
courses, fieldwork, internships, and language study, in terms of their graduate education and fulfilling their career goals. The fourth question asked students how important it was to take a full degree abroad.

\section{Importance of Academic Mobility to Graduate Education and Career Path to SSHRC Students}

Of the survey respondents, 64\% of doctoral fellows and 59\% of CGS recipients agreed with the statement that international academic mobility is important to their graduate education. In terms of fulfilling their career goals, 76\% of SSHRC fellows and 72\% of CGS recipients stated that international mobility was important.

These findings strongly support the high value that doctoral students attach to international mobility for their graduate studies, research, and career opportunities. Both sets of figures point to their possible interest in short-term international academic mobility. The significance of international academic mobility to students' career paths confirms that students' perceptions of mobility experiences are an advantage when seeking employment. These results suggest that doctoral students view international academic mobility as beneficial and closely linked to their future career opportunities in the academic, private, and public sectors and, thus, they warrant further attention.

\section{Ranking of Rationales Driving Academic Mobility Experiences}

Survey respondents were asked to rank 10 reasons why they were interested in academic mobility. Their reasons, in order of importance, were to: 1) attend conferences and workshops; 2) enhance career path; 3) gain life experiences; 4) participate in collaborative research; 5) take specialized courses; 6) seek employment; 7) access foreign supervisor; 8) collect data/conduct fieldwork; 9) learn a language; and 10) access specialized equipment.

The top three rationales (89\%-95\%) for both SSHRC fellows and CGS recipients were to attend conferences and workshops, enhance career path, and gain life experiences. The rationales that ranked in the middle range of importance (72\%-82\%) related to specific aspects of graduate work, such as to collect data, participate in collaborative research, access foreign supervisor, and seek employment. The lowest-ranked rationales were to learn a language and access equipment, although it is noteworthy that the majority of respondents (55\%-65\%) identified these rationales as being important. The ranking of the rationales presented some surprises and challenges in terms of how to respond to and support these priorities.

The high degree of importance that the survey respondents attached to attending conferences and workshops supports the priority of increasing the number of shortstay international visits; this would not only enhance students' research work, networking opportunities, and international exposure but also increase Canada's profile abroad. The barriers to mobility discussed in the following section also indicate that visits of less than a month may be more feasible, in terms of financing, personal responsibilities, and the time factor, and still provide value to students.

Given that the average age of completion of a SSHRC doctoral fellow is about 39 years, thus making career possibilities "front of mind," it is understandable that en- 
hancing their career path was one of the respondents' top rationales. The international nature of the job market today also demands skills and experiences that will increase employment opportunities, even if the employee never leaves the country. To this end, ways must be found to enhance doctoral students' international mobility by linking it more directly with future career opportunities.

The third top-ranking rationale relates to life experiences. Although this result may come as a surprise, it is consistent with other findings for both graduate and undergraduate students (Ackers et al., 2008; Avveduto, 2001). The exposure to other academic institutions, to foreign research counterparts, and to different cultures, customs, and political systems enhances students' world views, sharpens their analytical skills, and builds cross-cultural understanding.

The middle-ranked rationales relate to aspects of graduate work, specifically, collect data, engage in collaborative research, access foreign supervisor, and seek employment. The world of research is changing in terms of actors, partnerships, substance, and funding. The growing interdependence among countries, as well as the need to solve serious global problems, demands that international teams of researchers are able to address national and global issues. Major funding agencies, especially in Europe, recognize the fundamental role of international research networks for knowledge production and dissemination. Canada's future researchers and knowledge workers could benefit from increased exposure to international research networks in their fields of specialization. Having the opportunity to engage in collaborative research with key researchers allows doctoral students to share their research problems and findings, which may expand their contribution to and visibility in their discipline.

To learn a language and access equipment may have been ranked lower because these types of international experiences are more discipline specific and may not relate to the specializations of SSH doctoral students. However, it is noteworthy that the majority of respondents (55\%-65\%) identified these as being important rationales.

Although the rationales to study abroad are clear, several factors, or barriers, can prohibit Canadian SSH doctoral students from doing so. AUCC and other North American researchers have conducted studies on factors and barriers that impact study abroad, but few of these studies have looked specifically at doctoral mobility. Doctoral mobility is often different from that of undergraduate and master's students, who tend to be more interested in study abroad for courses and not for research. Given this difference, the factors impacting international academic mobility require special attention and are addressed in the next section.

\section{Factors Impacting International Academic Mobility}

Four major categories of factors impact international academic mobility: funding; academic; personal responsibilities and time; and culture and language. The factors that present obstacles to international mobility must be understood so they can be minimized in terms of policy, program design, logistics, and financial support. Because the types of issues included in each of the four categories vary, examples are provided in Table 3. These issues can either facilitate or act as barriers to international mobility, but for purposes of clarity and consistency, they are described here as barriers. 
Table 3

Factors/Barriers Impacting International Mobility

\begin{tabular}{|c|c|}
\hline & f Factors/Barriers to International Mobility \\
\hline Funding & $\begin{array}{l}\text { - student's personal finances are not sufficient for international mo- } \\
\text { bility } \\
\text { - student's debt load is too high } \\
\text { - student's other financial obligations prohibit international mobility } \\
\text { - student cannot obtain necessary external funds/grants/loans to fi- } \\
\text { nance the experience } \\
\text { - scholarship conditions do not include full degree abroad } \\
\text { - scholarship does not permit international mobility costs to be in- } \\
\text { cluded } \\
\text { - home institution provides no financial support }\end{array}$ \\
\hline Academic & $\begin{array}{l}\text { - home department/university lacks appropriate linkages/exchanges } \\
\text { with international partners to facilitate the experience } \\
\text { - home university does not recognize experience for academic credit } \\
\text { - home university lacks institutional services to support international } \\
\text { academic experiences at doctoral level } \\
\text { - doctoral supervisor is not internationally connected or supportive } \\
\text { - no foreign university has expertise in student's research area } \\
\text { - no appropriate balance between institution's reputation and align- } \\
\text { ment with student's research interests } \\
\text { - potential host institution's academic terms do not coincide with } \\
\text { home institution's terms, making short-term experience difficult to } \\
\text { coordinate } \\
\text { - potential host institution does not offer doctoral-level courses }\end{array}$ \\
\hline $\begin{array}{l}\text { Personal Re- } \\
\text { sponsibilities } \\
\text { and Time }\end{array}$ & $\begin{array}{l}\text { - student's part-time employment prevents spending time out of Can- } \\
\text { ada } \\
\text { - student's family responsibilities prevent going abroad for full degree } \\
\text { or short-term mobility experience } \\
\text { - student's health or disability considerations make international mo- } \\
\text { bility difficult } \\
\text { - student cannot find adequate health care to support international } \\
\text { mobility } \\
\text { - short-term mobility delays student's completion time of program } \\
\text { and start of career }\end{array}$ \\
\hline $\begin{array}{l}\text { Culture and } \\
\text { Language }\end{array}$ & $\begin{array}{l}\text { - student lacks necessary language skills for academic purposes } \\
\text { - student is uncomfortable with cultural aspects of living/working in } \\
\text { foreign environment } \\
\text { - student is concerned about safety of international travel } \\
\text { - student cannot find support for bringing family members }\end{array}$ \\
\hline
\end{tabular}


The survey asked students to rank how each of the four groups of factors would influence or, in cases where students had already studied abroad, had already influenced their ability to pursue academic experiences outside of Canada. More than 89\% of both SSHRC fellows and CGS recipients indicated that funding is the top barrier for pursuing international mobility, leaving no doubt that financial support is critical. Academic factors ranked second in importance, followed by the factors of personal responsibilities and time and, lastly, culture and language.

\section{Funding Issues}

Funding an international mobility experience is a key factor for most students, whether at the undergraduate or graduate level. The AUCC (2007) report on internationalization indicated that $89 \%$ of institutions surveyed identified the top barrier for Canadian students (both graduate and undergraduate) to study out of country as "lack of funds or financial support." For PhD students, there are additional concerns beyond what most undergraduates face, such as having to consider a spouse/partner, children, or perhaps aging parents. Ackers et al. (2008) recognized that doctoral students may also have professional responsibilities that inhibit their ability to study abroad. Regardless of the duration of study, PhD students have financial needs beyond travel, tuition, and room and board while abroad (Avveduto, 2001). Furthermore, scholarships and grants may not allow students to use funds for international research.

\section{Academic Issues}

Over $88 \%$ of the SSHRC fellows and CGS recipients who responded to the survey believed that academic issues were barriers to international mobility. The AUCC (2007) report on internationalization also indicated that after funding, the second most critical barrier was "curriculum at home university [was] too inflexible or [the] program too heavy." The third barrier identified in the AUCC report was "low awareness and commitment of faculty"; according to the AUCC survey, faculty were either unaware of university policies on study abroad or had a low commitment to international experiences. In both cases, this may mean that students are unable to receive credit and support for these experiences. Although receiving course credit may relate more to undergraduate students, the role that faculty play in doctoral students' international mobility is probably even more crucial than for undergraduate students and, as such, merits further investigation.

\section{Personal Responsibilities and Time Issues}

Over $80 \%$ of the SSHRC fellows and CGS recipients rated personal responsibilities and time as key factors. Nonetheless, only 11\% of these respondents rated them as extremely important, which suggests that these factor are not as central to the decision-making process as financial and academic issues.

Clearly, doctoral students are involved in a complex matrix of decision making when determining whether to go abroad, where to go, and for how long. Ackers et al. (2008) identified key factors related to the decision to go out of country as "life-course and family status, personal financial status, language competence, health status/disability and ethnicity" (p. 8). Ethnicity is a factor because of the cultural expectations 
placed on students, which vary according to their age, gender, and family status. In some cultures, for example, women must be nearby aging parents or grandparents in order to care for them, or they may not be permitted to live alone in another country. Given the diverse ethnic background of graduate students in Canada, attention should be given to how ethnicity influences ability and interest to study abroad.

\section{Culture and Language Issues}

Although culture and language factors ranked fourth in importance, 78\% of all respondents acknowledged their influence in decision making. It may be that SSHRC doctoral fellows choose to study in the United States, the United Kingdom, and France because these countries present fewer language and cultural issues. According to the AUCC (2007) report, 30\% of the institutions surveyed indicated "students lack [of] necessary language skills" as a major barrier to participating in study programs abroad.

In terms of destination countries, the choice of where to go is often influenced by the ability to access supervisors who have similar research interests, the discipline and topic of the $\mathrm{PhD}$ research, the required language skills, and the reputation of the supervisor, institution, or country in which the student wishes to study (Ackers et al., 2008). The OECD (2008) recognized that comparable education systems, proximity of the destination country, and recognition of degrees also influence the selection of the destination country.

These reasons may explain why $91 \%$ of SSHRC doctoral fellows taking a full degree abroad go to the United States (65\%) or the United Kingdom (26\%). For Canadian doctoral students, studying in the United States is understandably the most popular choice, as it offers the lowest start-up costs, its universities boast a strong global reputation, relocation is easier, and it presents the fewest cultural/language barriers. Another reason for the popularity of these two countries is the availability of scholarships to study in each of them. However, the fact that the majority of Canadian doctoral students go to either the United States or the United Kingdom raises the critical questions of potential brain drain and very limited exposure to other countries and cultures.

\section{AVAILABILITY OF SCHOLARSHIPS TO SUPPORT DOCTORAL MOBILITY}

The profile of Canadian SSH students and the financial factors that impact their decisions to study abroad indicate that scholarships are essential to the international academic mobility of Canadian graduate students. As noted in Table 4, the private and public sectors at the international, national, and provincial levels offer approximately 55 scholarship programs that can be used for international mobility by Canadian SSH doctoral students; however, this number is not indicative of how many actual awards are offered. The best unconfirmed estimate is that 2,400 awards are available annually. Of the 55 scholarship programs, 40 offer fewer than 20 awards per year. Because most of these programs are available to both doctoral and master's students in the social sciences and humanities, it is difficult to determine the number of awards explicitly targeted to SSH doctoral students. Their monetary value ranges from $\$ 1,000$ to $\$ 60,000$ per year, with the majority of scholarships under $\$ 20,000$ per year. Scholarship programs can support durations of study anywhere from three months to a full degree abroad, and many awards are renewable. 
Analyzing the availability of these scholarships was challenging, due to several limitations in the data collection. Although numerous opportunities may appear to be available, many scholarships are not transparent in how awards are distributed, making it difficult to assess the average number of scholarships awarded each year, specifically to SSH doctoral students and especially difficult in the case of programs that offer hundreds of awards. Therefore, the data focus on how many and what kinds of programs are available, rather than on how many awards are actually granted.

Most of the scholarship programs available to SSH doctoral students do not explicitly encourage study or research abroad. Scholarship programs that can be used for international mobility either permit their use for full degree abroad or short-term study or require justification for international study during the application process. The majority of awards are intended and are suitable for living and studying in Canada. Most often, they are not sufficient to cover costs related to international travel, research, and living expenses or the additional expenses doctoral students may have related to family responsibilities.

Flexible scholarship funding policies that allow for both short-term and long-term study are key to expanding international mobility opportunities for doctoral students. In many cases students need more than one award to fund an international experience; however, many scholarships have policies that limit the monetary value a student can hold from other sources, which penalizes students by restricting the scholarship amount they can receive from more than one award. Doctoral students interested in international academic mobility must consider all these policies when applying for scholarship programs.

Table 4

Scholarships Available to SSH Doctoral Students for International Mobility

\begin{tabular}{llcc}
\hline Public/Private & Scholarship Sponsor & Number of Programs & Number of Awards \\
\hline Public & International & 1 & 16 \\
& National & 14 & 780 (approx.) \\
& Provincial & 14 & 554 \\
& Institutional & Unknown & Unknown \\
Private & International & 4 & 178 \\
& National & 8 & 25 (approx.) \\
& Provincial & 3 & 450 (approx.) \\
& Institutional (outside Canada) & 11 & 134 \\
\hline
\end{tabular}

\section{Public and Private Scholarships}

Although public and private scholarship programs are evenly split, the majority of awards that can be used for the international mobility of SSH doctoral students come from provincial and federal funding, and most of those awards come from SSHRC. There is no doubt that SSHRC grants are fundamental to providing international mobility opportunities for SSH doctoral students. 
There are very few public and private partnerships that explicitly provide scholarships linked to international mobility. Because most scholarships do not explicitly encourage international mobility, scholarships used for international study are open. The openness of these types of scholarships may encourage Canadian doctoral mobility trends to follow world trends, with most Canadian students going to the United States. There are no apparent scholarship policies in place to prevent brain-drain issues, particularly concerning mobility to the United States, and most public scholarships do not require public service upon degree completion.

The few public scholarships that are destination and institution specific include the Foreign Government Awards Program, the Commonwealth Scholarships, and the Fulbright Scholar Program. Among the private scholarships, roughly 230 awards are institution and country specific. Of the country-specific awards, most are to Commonwealth countries or to the United States, again following world trends. Unfortunately, this emphasis on U.S. and U.K. scholarships misses opportunities to build ties with other countries.

\section{Eligibility for Awards}

In proportion to the number of scholarships offered in all disciplines, very few scholarships are specifically aimed at supporting the social sciences and humanities. Because most of these scholarships are available to both master's and doctoral students, the availability of scholarships for master's students proactively builds international linkages that may be beneficial if the students continue on with doctoral studies.

Overall, very few scholarships support international mobility exclusively for doctoral studies, and even fewer focus on the international mobility of doctoral students in the social sciences and humanities. As the national CGS survey demonstrates, SSH doctoral students have an interest in incorporating an international experience into their studies. Thus, an increase in funding programs that support SSH doctoral study is needed.

\section{IMPLICATIONS FOR POLICY AND FURTHER RESEARCH}

A review of the literature and policy documents on international mobility reveals a strong focus on undergraduate rather than graduate level mobility. In fact, an unexpected finding of this study is the dearth of information on doctoral student mobility, whether it is participation rates, preferred modes and destinations, benefits and risks, outcomes, impact on career choices, or barriers and facilitators.

Study abroad is currently viewed primarily as an undergraduate student experience, a view that overlooks important research and networking opportunities that the international mobility of doctoral students can provide. Although factors impacting mobility, such as financial constraints, are common at both undergraduate and graduate levels of international academic mobility, differences in doctoral students' expectations and priorities demonstrate that institutional and national policies should address undergraduate and graduate mobility separately. For example, the new CGS Foreign Study Supplement uses an undergraduate model of funding one semester of study abroad at a foreign university that may or may not respond to the students' interests, as expressed in the national CGS survey, for short-term participation in a conference or workshop or for collecting field data. 
Besides demonstrating that funding is the most significant factor for SSH doctoral mobility, this study has identified a lack of public focus on the international mobility of Canadian graduate students. Notwithstanding the research councils' databases, very few data sources exist on Canadian graduate student international mobility. To further understand the mobility of Canadian students, a national tracking system, based on institutional databases, is necessary to collect information on the destination, duration, and types of international experiences of Canadian students.

More attention needs to be given to scholarships for Canadian students to participate in short-term or full-time study abroad. Indeed, there are several opportunities to improve the current funding of international mobility for SSH doctoral students. First, more public awards could explicitly encourage international study. Second, additional funding amounts for short-term international study and research would have individual, institutional, and national benefits. Third, policies allowing students to hold multiple scholarships for international academic experiences may encourage more doctoral students to study abroad. Fourth, more scholarships should be linked to Canadian political and economic strategies; public attention to SSH doctoral scholarships could encourage the development of international research linkages in strategic geographical regions and attend to global issues important to Canada. Fifth, a model for how best to support international mobility is lacking.

There is no doubt that the international mobility of Canadian doctoral students requires more attention. As Europe strengthens its doctoral programming (Kehm, 2007), and the United States and the United Kingdom continue to receive the majority of the internationally mobile students, Canada must consider the impact of globalization on its graduate students. In addition to playing an important role in building international research partnerships, Canadian doctoral students contribute a Canadian perspective to global issues.

\section{REFERENCES}

Ackers, L., Bill, B., \& Guther, J. (2008). Doctoral mobility in the social sciences. A summary report to NORFACE. Liverpool, UK: University of Liverpool, European Law and Policy Research Group. Retrieved February 17, 2010 from http://www.liv.ac.uk/law/ elprg/docs/NORFACE_SUMMARY_REPORT_FINAL_June_08_Agreed_with_ESRC.pdf

Altbach, P., \& Knight, J. (2007). The internationalization of higher education: Motivations and realities. Journal of Studies in International Education, 11(34), 290-305.

Association of Universities and Colleges of Canada (AUCC). (2007). Canadian universities and international student mobility. Ottawa, ON: Author. Retrieved October 18, 2007, from http://www.aucc.ca/_pdf/english/publications/student_mobility_2007_e.pdf

Avveduto, S. (2001). International mobility of PhDs. Rome: National Research Council. Retrieved October 21, 2007 from http://www.oecd.org/dataoecd/33/49/2096794.pdf

Bhandari, R., \& Blumenthal, P. (2009). Global student mobility: Moving towards brain exchange. In R. Bhandari \& S. Laughlin (Eds.), Higher education on the move: New developments in global mobility (pp. 1-14). New York: IIE.

Dwyer, M., \& Peters, C. (2004). The benefits of study abroad. Transitions Abroad, 37(5), 56-58. 
European Commission (2010). The Erasmus Programme. Brussels: European Commission. Retrieved May 9, 2010 from http://ec.europa.eu/education/lifelong-learningprogramme/doc80_en.htm

Gauthier, B. (2009). Canada Graduate Scholarships (CGS) Program and Related Programs Review. Ottawa, ON: CIHR, SSHRC, NSERC.

Gluszynski, T., \& Peters, V. (2005). Survey of earned doctorates: A profile of doctoral degree recipients. Ottawa, ON: Statistics Canada, Center for Education Statistics. Retrieved September 20, 2007 from http://www.statcan.ca/cgi-bin/imdb/p2SV.pl?Fun ction=getSurvey\&SDDS=3126\&lang $=e n \& d b=I M D B \& d b g=f \& a d m=8 \& d i s=2$ ]

Industry Canada. (2007). Mobilizing science and technology to Canada's advantage. Ottawa, ON: Author.

Jaschik, S. (2007, October). The mobile international student. Inside Higher Education. Retrieved October 15, 2007 from http://www.insidehighered.com/ news/2007/10/10/mobile

Kehm, B. (2007). Quo vadis doctoral education? New European approaches in the context of global changes. European Journal of Education, 42(3), 307-319.

Knight, J. (2008). Higher education in turmoil: The changing world of internationalization. Rotterdam, Netherlands: Sense Publishers.

Knight, J., \& Madden, M. (2008). International academic mobility experiences for Canadian social science and humanities doctoral students. Unpublished report, Social Sciences and Humanities Research Council of Canada, Ottawa, ON.

Natural Sciences and Engineering Research Council of Canada (NSERC). (2009). Strategy for partnerships and innovation. Ottawa, ON: Author. Retrieved February 11, 2010 from http://www.nsercpartnerships.ca/_docs/SPI_e.pdf

Observatory on Borderless Higher Education (OBHE). (2007). Realising the global university. Part I. London: Author.

Organization for Economic Co-operation and Development (OECD). (2008). Education at a glance. Paris: Author.

Social Sciences and Humanities Research Council of Canada (SSHRC). (2005). Knowledge council: SSHRC 2006-2011. Ottawa, ON: Author. Retrieved February 11, 2010 from http://dsp-psd.pwgsc.gc.ca/Collection/CR22-42-2006E.pdf

Social Sciences and Humanities Research Council of Canada (SSHRC). (2006). International policy and strategy. Ottawa, ON: Author. Retrieved August 24, 2007 from http://www.sshrc.ca/SITE/about-crsh/publications/international_policy_e.pdf

Statistics Canada. (2005). Survey of earned doctorates. Ottawa, ON: Author.

Statistics Canada. (2007). Post secondary student information system. Ottawa, ON: Author.

Teichler, U. (2004). The changing debate on internationalization of higher education. Higher Education, 48(1), 5-26. 
UNESCO. (2006). Global education digest. Paris: Author. Retrieved November 28, 2007 from http://www.uis.unesco.org/TEMPLATE/pdf/ged/2006/GED2006.pdf

Verbik, L. (2007). International student mobility: Patterns and trends. London: Observatory on Borderless Higher Education.

Williams, G. (2008). Canada. In M. Nerad \& M. Heggalund (Eds.), Towards a global doctorate? Forces and forms of change in doctoral education worldwide (pp. 249-277). Seattle: University of Washington Press.

\section{CONTACT INFORMATION}

Jane Knight

Department of Theory and Policy Studies

OISE, University of Toronto

Toronto, ON

M5S 1V6

janeknight@sympatico.com

Jane Knight is an adjunct professor at the Ontario Institute for Studies in Education at the University of Toronto who focuses her research on the international dimension of higher education at the institutional, national, regional, and international levels. Her work in over 60 countries with universities, foundations, the World Bank, UN agencies, and higher education organizations helps to bring a comparative, development, and international perspective to her research, teaching, policy work, and numerous publications. She was a 2007-2008 Fulbright New Century Scholar, and she sits on the advisory boards of several international organizations and journals.

Meggan Madden is a doctoral candidate who specializes in higher education and comparative, international, and development education at the Ontario Institute for Studies in Education at the University of Toronto. She has worked for several years on international student mobility issues, both receiving and sending students, in universities in the United States. Her current research focus is the regionalization of higher education, particularly in relation to quality assurance mechanisms in higher education.

\section{ACKNOWLEDGEMENT}

Appreciation is extended to the Social Sciences and Humanities Research Council (SSHRC) for permission to use some of the findings in this article. For a summary of the full study, see www.sshrc.ca

\section{NOTES}

1. SSHRC scholarship applications are submitted in the fall. Awards can be granted during the first three years of the program, which allows students to apply a year before their doctoral studies begin.

2. $2 \%$ of respondents self-identified as being from an interdisciplinary field. 